\title{
Novel Three-Phase PWM Voltage-Fed Rectifier with an Auxiliary Resonant Commutated Pole Link
}

\author{
Ke-Qing $\mathrm{Qu}^{\dagger}$ and Jin-Bin Zhao* \\ $\grave{\dagger}^{*}$ College of Electrical Engineering, Shanghai University of Electric Power, Shanghai, China
}

\begin{abstract}
A novel auxiliary resonant commutated pole (ARCP) link for three-phase PWM voltage-fed converter is presented. The ARCP link consists of two auxiliary switches, one resonant inductance, and six diodes, which is simpler than the conventional ARCP designs. Based on the phase and amplitude control, the proposed converter can take a minimum switching times PWM method, which results in reduced losses and a simplified control. In addition, the zero-voltage resonance modes are analyzed. Finally, simulation and experimental results show that the system can realize zero-voltage switching with a unity power factor.
\end{abstract}

Key words: ARCP, PFC, Zero voltage switching

\section{INTRODUCTION}

In order to obtain high power factor transmission of electric power and reduced switching loss simultaneously, soft-switching PWM converters have become an effective solution among modern power conversion devices for suppressing harmonic pollution, restraining electromagnetic interference and increasing efficiency.

There are a variety of topologies and control strategies for designing three phase soft switching PWM converters. Among these, the zero-voltage switching (ZVS) converters can be broadly divided into two categories according to the different bus links in achieving resonance: the resonant DC link system (RDCLS) [1]-[3] and the resonant pole system (RPS) [4]-[10]. The RDCLS uses a resonant circuit composing of resonant inductors paralleled on the DC bus and snubber capacitors paralleled on the power switches, which achieves a periodical zero voltage on the DC bus as a basis for the power switches turning-on. This solution is simple in structure. However, it affects utilization of the bus voltage. In comparison the RPS changes the resonant circuit being with resonant inductors paralleled in three-phase bridges on $\mathrm{AC}$ bus links, which scales the bridge input

Manuscript received Dec. 9, 2013; accepted Apr. 27, 2014

Recommended for publication by Associate Editor Trillion Q Zheng.

†Corresponding Author: kqqu@shiep.edu.cn

Tel: +86-21-35305346, Shanghai University of Electric Power

${ }^{*}$ College of Electrical Engineering, Shanghai University of Electric Power, China voltage either at zero or at bus working voltage periodically, and so the power switches acts at zero voltage.

The auxiliary resonant commutated pole (ARCP) converters among the RPS solutions have some advantages, such as higher efficiency, lower voltage or current stress to the power switches and fly-wheel diodes. However, for the conventional ARCP three-phase PWM converter, each bridge with one resonant circuit has six auxiliary switches, three resonant inductors and six diodes, which lead to a complex structure. Some papers suggests a simplification of the structure of RPS converters so as to promoting their application [11]-[17].

A simplified ARCP for three-phase PWM rectifier is proposed in this paper, which includes two auxiliary switches, one resonant inductor and six diodes. Based on amplitude and phase control, the rectifier applies the least switching times PWM mode, which ensures a normal resonance to simplify the control, and improved efficiency. The six power switches in the three-phase bridges act under the ZVS state, while the two auxiliary switches work under the zero current switching (ZCS) state. The effectiveness of the proposed strategy is demonstrated through simulation and experiment results for a $1 \mathrm{~kW}$ PWM rectifier.

\section{MAIN CIRCUIT AND PWM CONTROL STRATEGY}

Fig. 1 shows the main circuit of the proposed ARCP three-phase PWM rectifier, where $e_{\mathrm{R}}, e_{\mathrm{S}}$ and $e_{\mathrm{T}}$ refer to 


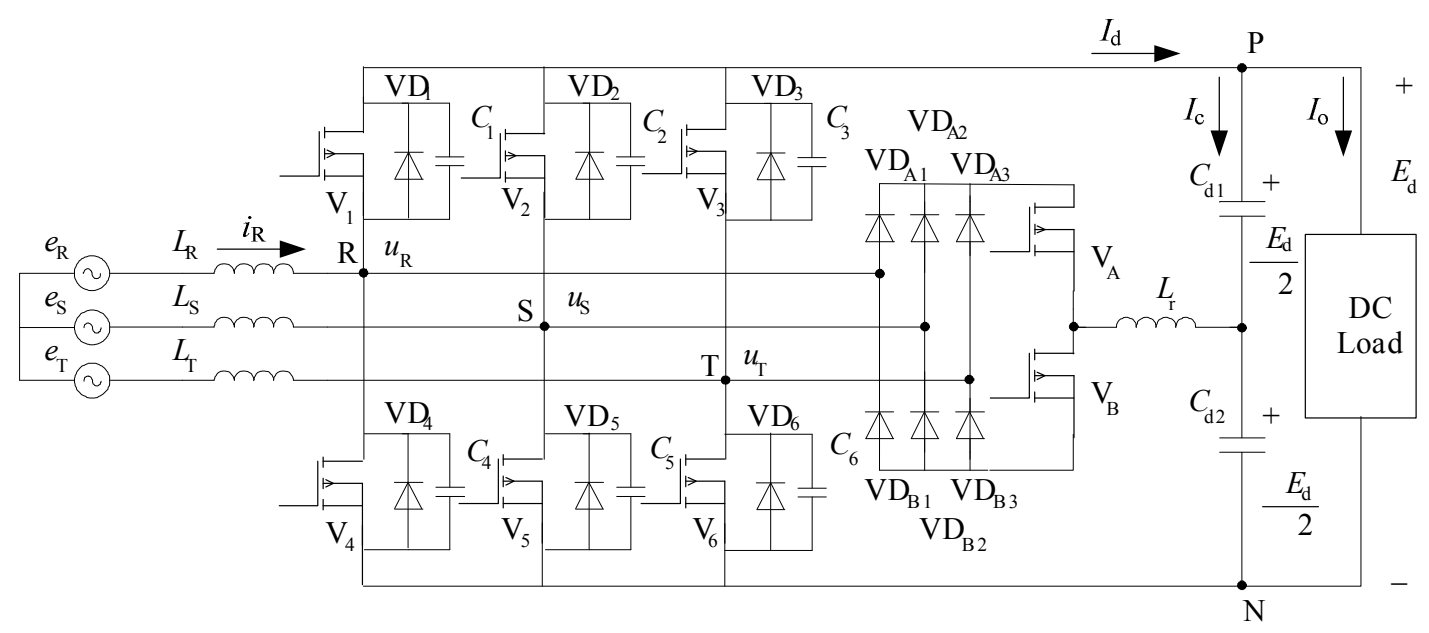

Fig. 1. Main circuit of the ARCP rectifier.

the three-phase AC source. The three-phase bridge circuit includes series inductances $L_{\mathrm{R}}, L_{\mathrm{S}}$ and $L_{\mathrm{T}}$, power switches $\mathrm{V}_{1} \sim \mathrm{V}_{6}$, fly-wheel diodes $\mathrm{VD}_{1} \sim \mathrm{VD}_{6}$, and snubber capacitors $\mathrm{C}_{1} \sim \mathrm{C}_{6}$. The resonance circuit is composed of diodes $\mathrm{VD}_{\mathrm{A} 1} \sim \mathrm{VD}_{\mathrm{A} 3}$ and $\mathrm{VD}_{\mathrm{B} 1} \sim \mathrm{VD}_{\mathrm{B} 3}$, auxiliary switches $\mathrm{V}_{\mathrm{A}}$ and $\mathrm{V}_{\mathrm{B}}$, split-capacitor capacitors $C_{\mathrm{d} 1}$ and $C_{\mathrm{d} 2}$, and a resonant inductor $L_{\mathrm{r}}$. The DC voltage on the load is defined as $E_{\mathrm{d}}$ and $E_{\mathrm{d}} / 2$ as the voltage on $C_{\mathrm{d} 1}$ and $C_{\mathrm{d} 2}$ respectively. The fundamental components of the phase voltage after PWM are $u_{\mathrm{R}}, u_{\mathrm{S}}$ and $u_{\mathrm{T}}$. The PWM control strategies of the rectifier are described in detail hereafter.

The rectifier applies amplitude and phase control to achieve power factor correction while the phase voltage and phase current are kept in phase. This complies with the following expressions:

$$
\left\{\begin{array}{l}
u_{\mathrm{R}}(t)=M \sin \left(\omega t-\theta_{0}\right) \\
u_{\mathrm{S}}(t)=M \sin \left(\omega t-\theta_{0}-\frac{2 \pi}{3}\right) \\
u_{\mathrm{T}}(t)=M \sin \left(\omega t-\theta_{0}-\frac{4 \pi}{3}\right)
\end{array}\right.
$$

Where $M$ is the modulation ratio, and $\theta_{0}$ is the offset angle between $u_{\mathrm{R}}$ and $e_{\mathrm{R}}$.

Fig. 2 shows the key waveforms, where $i_{\mathrm{R}}, i_{\mathrm{S}}$ and $i_{\mathrm{T}}$ are the three-phase currents from the source, and $u_{\mathrm{R}}, u_{\mathrm{S}}$ and $u_{\mathrm{T}}$ are the three-phase modulation waves. On the other hand, $u_{G 1} \sim u_{G 6}$, $u_{G \mathrm{~A}}$ and $u_{G \mathrm{~B}}$ are the gate drive signals of the power switches $V_{1} \sim V_{6}, V_{A}$ and $V_{B}$. It can be seen from Fig.1 that each power switch in the three-phase bridges has one paralleled snubber capacitor that prevents immediate voltage changes. The switches always turn off in the ZVS state. Therefore, only turning-on of the power devices in the ZVS state is necessary. To conveniently achieve closing of the switches at the same time, in Fig. 2 the modulation method adopts a saw-tooth carrier with alternative positive and negative slopes instead of the conventional triangular carrier. It is defined here that

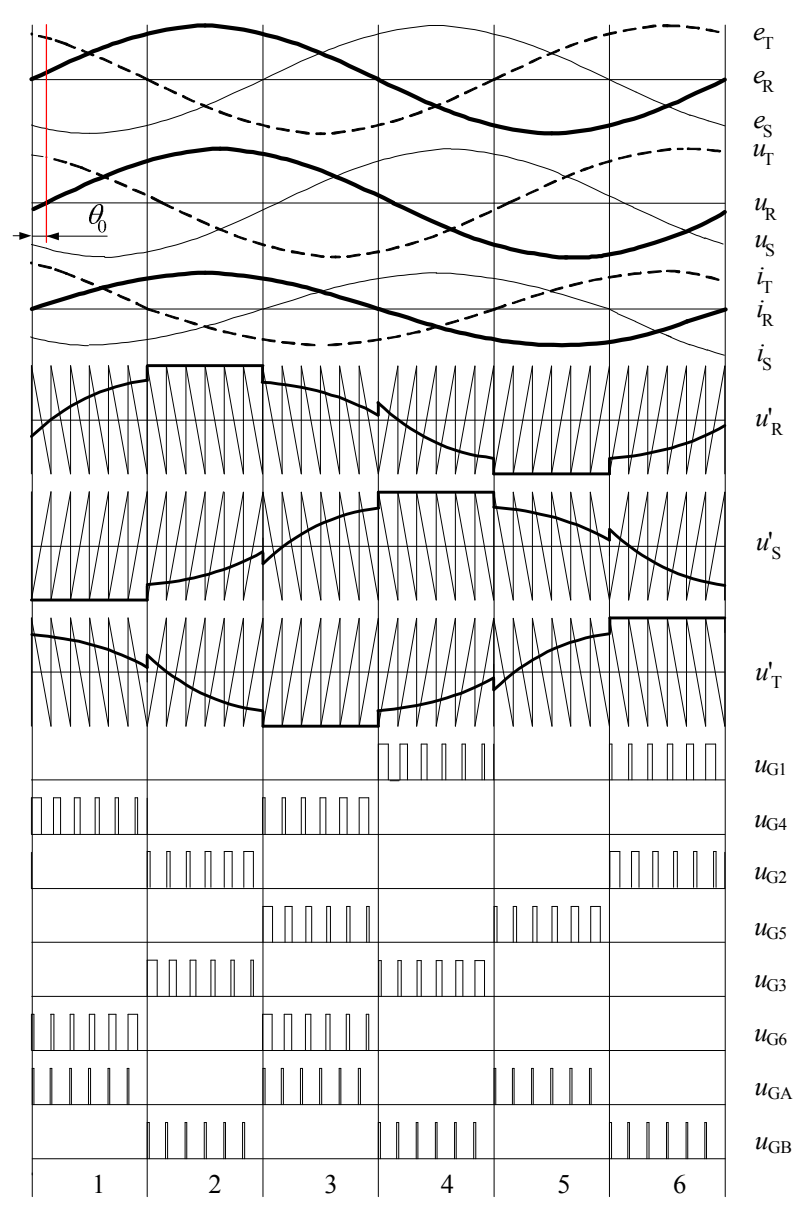

Fig. 2. Key waveforms of proposed converter.

when it flows to the power device, the phase current is positive and the saw-tooth carrier adopts a positive slope, or phase current is negative and the saw-tooth carrier adopts a negative slope. The turning-on of the power devices can be converged at the vertical edges of the saw-tooth carrier. When compared with the triangular carrier, the resonance control becomes easier and is reduces $1 / 3$ resonant times. 
The minimum switching time PWM mode is adopted to ensure auxiliary resonant converting. In Fig. 2 the per cycle of $[0,2]$ can be divided into six sections according to the difference between a phase current direction to the other two phase currents. For instance in section 2, since the phase R current is at maximum, it flows though diode $\mathrm{VD}_{1}$ in parallel with switch $\mathrm{V}_{1}$. Then in the phase $\mathrm{R}$ bridge, the two power switches $V_{1}$ and $V_{4}$ are kept off. Therefore, the switching times can be cut down $1 / 3$ when compared to the conventional methods. The control strategy achieves easier control of the system.

Three phase voltage modulation wave signals $u_{\mathrm{R}}, u_{\mathrm{S}}$, and $u_{\mathrm{T}}$ are generated by the line voltage. According to the six sections mentioned above and by combining equation (1), the following expressions can be derived:

Section 1

$$
\left\{\begin{array}{l}
u_{\mathrm{R}}^{\prime}(t)=u_{\mathrm{R}}(t)-u_{\mathrm{S}}(t)-1=\sqrt{3} M \cos \left(\omega t-\theta_{0}-\frac{\pi}{3}\right)-1 \\
u_{\mathrm{S}}^{\prime}(t)=-1 \\
u_{\mathrm{T}}^{\prime}(t)=u_{\mathrm{T}}(t)-u_{\mathrm{S}}(t)-1=\sqrt{3} M \cos \left(\omega t-\theta_{0}\right)-1
\end{array}\right.
$$

Section 2

$$
\left\{\begin{array}{l}
u_{\mathrm{R}}^{\prime}(t)=+1 \\
u_{\mathrm{S}}^{\prime}(t)=u_{\mathrm{S}}(t)-u_{\mathrm{R}}(t)+1=-\sqrt{3} M \cos \left(\omega t-\theta_{0}-\frac{\pi}{3}\right)+1 \\
u_{\mathrm{T}}^{\prime}(t)=u_{\mathrm{T}}(t)-u_{\mathrm{R}}(t)+1=-\sqrt{3} M \cos \left(\omega t-\theta_{0}-\frac{2 \pi}{3}\right)+1
\end{array}\right.
$$

Section 3

$$
\left\{\begin{array}{l}
u_{\mathrm{R}}^{\prime}(t)=u_{\mathrm{R}}(t)-u_{\mathrm{T}}(t)-1=\sqrt{3} M \cos \left(\omega t-\theta_{0}-\frac{2 \pi}{3}\right)-1 \\
u_{\mathrm{S}}^{\prime}(t)=u_{\mathrm{S}}(t)-u_{\mathrm{T}}(t)-1=\sqrt{3} M \cos \left(\omega t-\theta_{0}\right)-1 \\
u_{\mathrm{T}}^{\prime}(t)=-1
\end{array}\right.
$$

Section 4

$$
\left\{\begin{array}{l}
u_{\mathrm{R}}^{\prime}(t)=u_{\mathrm{R}}(t)-u_{\mathrm{S}}(t)+1=\sqrt{3} M \cos \left(\omega t-\theta_{0}-\frac{\pi}{3}\right)+1 \\
u_{\mathrm{S}}^{\prime}(t)=+1 \\
u_{\mathrm{T}}^{\prime}(t)=u_{\mathrm{T}}(t)-u_{\mathrm{S}}(t)+1=\sqrt{3} M \cos \left(\omega t-\theta_{0}\right)+1
\end{array}\right.
$$

Section 5

$$
\left\{\begin{array}{l}
u_{\mathrm{R}}^{\prime}(t)=-1 \\
u_{\mathrm{S}}^{\prime}(t)=u_{\mathrm{S}}(t)-u_{\mathrm{R}}(t)-1=-\sqrt{3} M \cos \left(\omega t-\theta_{0}-\frac{\pi}{3}\right)-1 \\
u_{\mathrm{T}}^{\prime}(t)=u_{\mathrm{T}}(t)-u_{\mathrm{R}}(t)-1=-\sqrt{3} M \cos \left(\omega t-\theta_{0}-\frac{2 \pi}{3}\right)-1
\end{array}\right.
$$

Section 6

$$
\left\{\begin{array}{l}
u_{\mathrm{R}}^{\prime}(t)=u_{\mathrm{R}}(t)-u_{\mathrm{T}}(t)+1=\sqrt{3} M \cos \left(\omega t-\theta_{0}-\frac{2 \pi}{3}\right)+1 \\
u_{\mathrm{S}}^{\prime}(t)=u_{\mathrm{S}}(t)-u_{\mathrm{T}}(t)+1=-\sqrt{3} M \cos \left(\omega t-\theta_{0}\right)+1 \\
u_{\mathrm{T}}^{\prime}(t)=+1
\end{array}\right.
$$

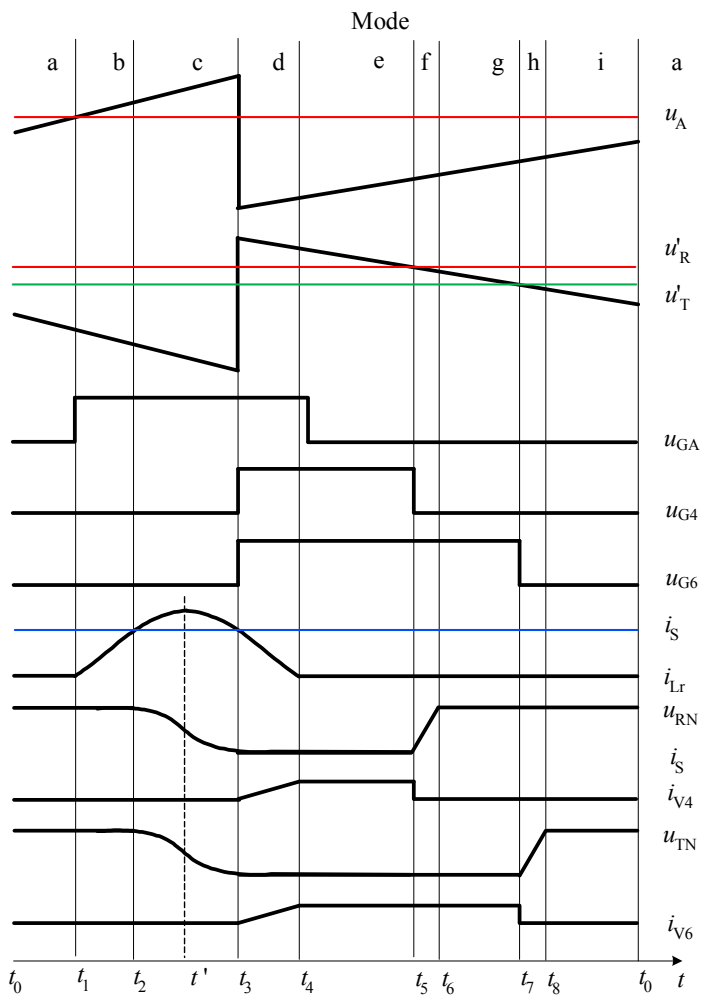

Fig. 3. Waveforms of the ARCP circuit.

From the above analysis, by comparing the modulation wave to the saw-tooth carrier, the gate drive signals $u_{G 1} \sim u_{G 6}$ are obtained for each power switch in all of the bridges. This is shown in Fig. 2.

\section{RESONANCE MODE}

In Fig. 2, when one phase current is negative while the other two are positive, the power switch $\mathrm{V}_{\mathrm{A}}$ is working and resonance happens. Conversely, if one phase current is positive while the other two are negative, $V_{B}$ is working. Since the respective phases' currents are direct opposite, the ARCP circuit also has two operation modes, one of which is described in detail below.

Take section 1 as an example, when the three phase current directs as $i_{\mathrm{S}}>0, i_{\mathrm{R}}>0$, and $i_{\mathrm{T}}<0$, the power switches $\mathrm{V}_{2}$ and $\mathrm{V}_{5}$ in the $\mathrm{T}$ phase bridge are off, $\mathrm{V}_{1}$ and $\mathrm{V}_{2}$ in the $\mathrm{R}$ and $\mathrm{S}$ phases upper bridge are off, while $\mathrm{V}_{4}$ and $\mathrm{V}_{6}$ in the lower bridge and the auxiliary switch $\mathrm{V}_{\mathrm{A}}$ are on.

Fig. 3 shows the waveforms of the ARCP circuit. In per cycle of the carrier, 9 modes can be separated by the main circuit switching manners, which are shown in Fig. 4. Since the frequency of the rectifier carrier is much higher than the grid frequency, the input current in per cycle can be considered constant, and is represented by the constant current source $i_{\mathrm{s}}$. Meanwhile, since the split-capacitors $C_{\mathrm{d} 1}$ and $C_{\mathrm{d} 2}$ are large enough, their voltages are considered constant, and it represented by the voltage source $E_{\mathrm{d}} / 2$. 


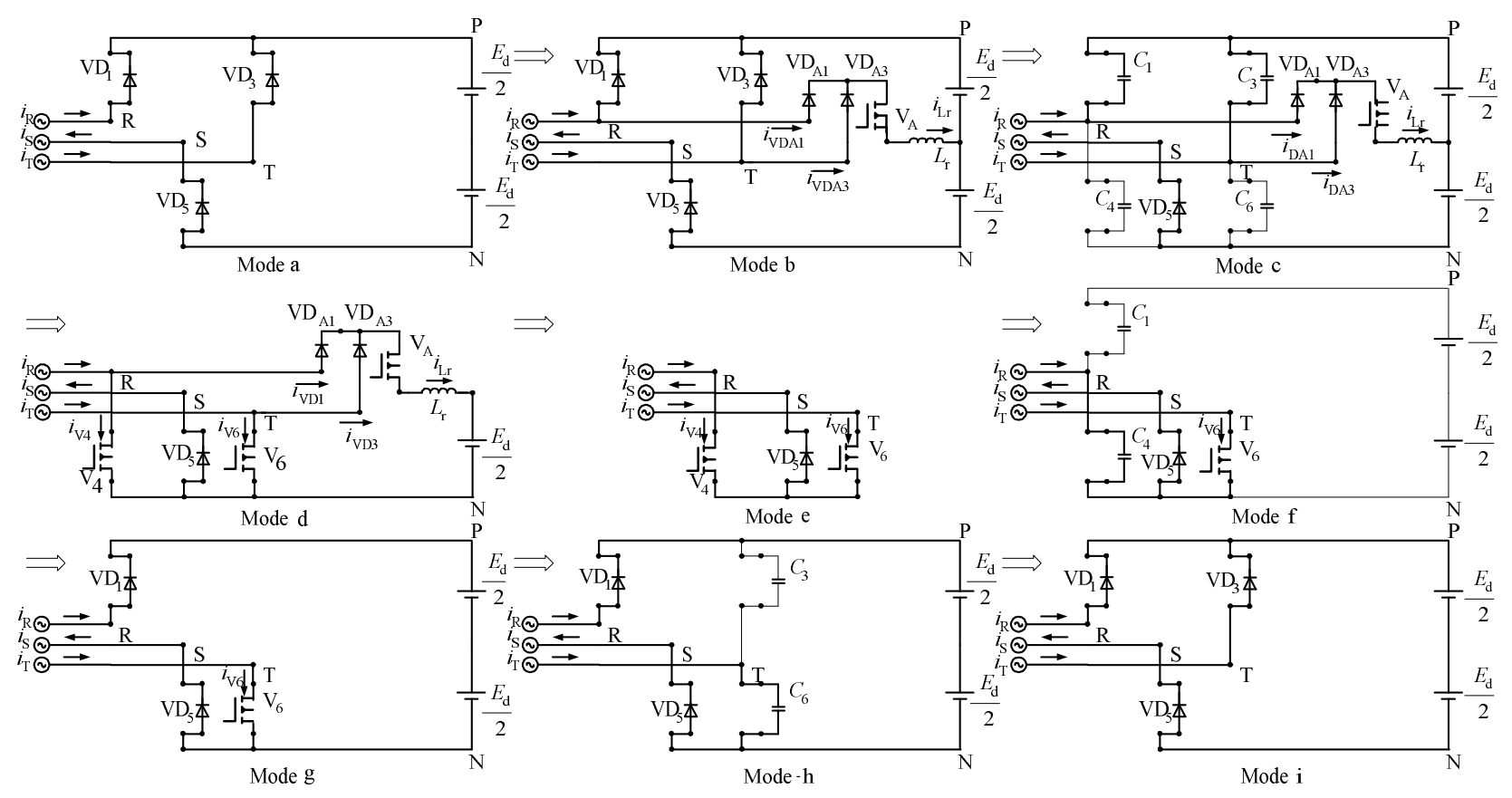

Fig. 4. Operating modes.

\section{A. Resonance Analysis}

Mode a $\left(t_{0} \sim t_{1}\right)$ : At the stable state, power is provided to the load from the three phase source and series inductors $L_{\mathrm{R}}, L_{\mathrm{S}}$ and $L_{\mathrm{T}}$. Each phase current flows through the fly-wheel diodes $\mathrm{VD}_{2}, \mathrm{VD}_{3}$ and $\mathrm{VD}_{5}$ respectively.

Mode $\mathrm{b}\left(t_{1} \sim t_{2}\right)$ : When $\mathrm{V}_{\mathrm{A}}$ switches on at $t_{2}$, the voltage on $L_{\mathrm{r}}$ is $E_{\mathrm{d}} / 2$, and the current $i_{\mathrm{Lr}}$ increases gradually so that $\mathrm{V}_{\mathrm{A}}$ is switched on under zero current. When $i_{\mathrm{Lr}}=i_{\mathrm{DA} 1}+i_{\mathrm{DA} 3} \geq i_{\mathrm{R}}+i_{\mathrm{T}}\left(=\left|i_{\mathrm{S}}\right|\right)$, diodes $\mathrm{VD}_{1}$ and $\mathrm{VD}_{3}$ are shut off at the zero current state.

Mode $\mathrm{c}\left(t_{2} \sim t_{3}\right)$ : Resonance happens on both $L_{\mathrm{r}}$ and the snubber capacitors of $\mathrm{R}$ and $\mathrm{T}$ phases. For $\mathrm{R}$ phase, $C_{1}$ is charging and $C_{4}$ discharging, while for $\mathrm{T}$ phase, $C_{3}$ is charging and $C_{6}$ discharging. During the weakening of the discharge, $i_{\mathrm{Lr}}$ increases and then decreases until the discharging of $C_{4}$ and $C_{6}$ finish at a time when the phase voltage equals zero.

Mode $\mathrm{d}\left(t_{3} \sim t_{4}\right)$ : At $t=t_{3}, u_{\mathrm{RN}}$ and $u_{\mathrm{TN}}$ decrease to zero, and $i_{\mathrm{Lr}}=\left|i_{\mathrm{S}}\right|$. Therefore, $\mathrm{V}_{4}$ and $\mathrm{V}_{6}$ are switched on under zero voltage and zero current.

The voltage on the inductor is $E_{\mathrm{d}} / 2$. Therefore, the power directs to source $E_{\mathrm{d}} / 2$ and $i_{\mathrm{Lr}}$ decreases. At the same time, as $i_{\mathrm{V} 4}$ and $i_{\mathrm{V} 6}$ increase, power is transmitted to the series inductors $L_{\mathrm{R}}, L_{\mathrm{S}}$ and $L_{\mathrm{T}}$. As a result, the current meets with the relations below:

$$
\left|i_{\mathrm{S}}\right|=i_{\mathrm{R}}+i_{\mathrm{T}}=\left(i_{\mathrm{V} 4}+i_{\mathrm{DA} 1}\right)+\left(i_{\mathrm{V} 4}+i_{\mathrm{DA} 3}\right)=\left(i_{\mathrm{V} 4}+i_{\mathrm{V} 4}\right)+i_{\mathrm{Lr}}
$$

Since $i_{\mathrm{S}}$ remains constant, $i_{\mathrm{Lr}}=0$ when $\left|i_{\mathrm{S}}\right|=i_{\mathrm{R}}+i_{\mathrm{T}}=i_{\mathrm{V} 4}+i_{\mathrm{V} 6}$.

Mode e $\left(t_{4} \sim t_{5}\right): i_{\mathrm{Lr}}$ continues to decrease until its direction is reversed. Since diode $\mathrm{VD}_{\mathrm{A} 1}$ and $\mathrm{VD}_{\mathrm{A} 3}$ are off in reverse, the current on $i_{\mathrm{Lr}}$ remains zero. As a result, $\mathrm{V}_{\mathrm{A}}$ is switched off under zero current.

Mode $\mathrm{f}\left(t_{5} \sim t_{6}\right)$ : Since the voltage on capacitor $C_{4}$ is zero and is kept there, $\mathrm{V}_{4}$ can be switched off under zero-voltage. At this time $i_{\mathrm{V} 4}$ decreases to zero, $C_{4}$ starts charging and $C_{1}$ starts discharging.

Mode $\mathrm{g}\left(t_{6} \sim t_{7}\right)$ : At $t_{6}, u_{\mathrm{RN}}$ increases to $E_{\mathrm{d}}$, and the voltage on $C_{1}$ is zero. At this time, power is transmitted to the load form the $R$ and $S$ phase sources and the series inductors $L_{\mathrm{R}}$ and $L_{\mathrm{S}}$. As a result, diode $\mathrm{VD}_{1}$ is switched on by the forward voltage.

Mode $\mathrm{h}\left(t_{7} \sim t_{8}\right)$ : Similar to mode $\mathrm{f}, \mathrm{V}_{6}$ is switched off under zero voltage. Meanwhile, $i_{\mathrm{V} 6}$ decrease to zero, $C_{6}$ start charging and $C_{3}$ starts discharging.

Mode i $\left(t_{8} \sim t_{0}\right)$ : Similar to mode g, diode $\mathrm{VD}_{3}$ is switched on. At this time, operation returns to mode a.

\section{B. Mathematical Analysis of the Resonance}

1) Mathematical Analysis for Mode $b$ : Due to the initial conditions $i_{\mathrm{Lr}}\left(t_{1}\right)=0$ and $u_{\mathrm{Lr}}=E_{\mathrm{d}} / 2$, the voltage complies with:

$$
L_{\mathrm{r}} \frac{\mathrm{d} i_{\mathrm{Lr}}}{\mathrm{d} t}=\frac{E_{\mathrm{d}}}{2}
$$

and it can be derived that:

$$
i_{\mathrm{Lr}}(t)=\frac{E_{\mathrm{d}}}{2 L_{\mathrm{r}}}\left(t-t_{1}\right)
$$

at $t=t_{2}, i_{\mathrm{Lr}}\left(t_{2}\right)=\left|i_{\mathrm{S}}\right|$, i.e.

$$
i_{\mathrm{Lr}}\left(t_{2}\right)=\frac{E_{\mathrm{d}}}{2 L_{\mathrm{r}}}\left(t_{2}-t_{1}\right)=\left|i_{\mathrm{S}}\right|
$$

Thus: 


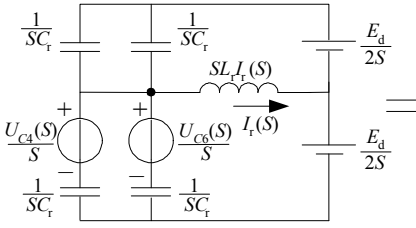

(a)

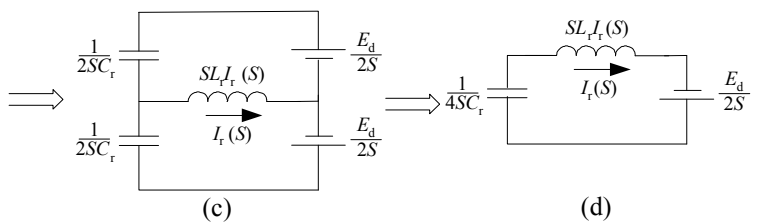

Fig. 5. Diagrams of simple equivalent resonant circuit.

$$
\Delta t_{2}=t_{2}-t_{1}=\frac{2 L_{\mathrm{r}}\left|i_{\mathrm{S}}\right|}{E_{\mathrm{d}}}
$$

2) Mathematical Analysis for Mode c: Fig. 5 shows diagrams of a simple equivalent resonant circuit. Assume that each capacitor is $C_{\mathrm{r}}$, and that the initial conditions are $u_{\mathrm{C} 4}\left(t_{2}\right)=u_{\mathrm{C} 6}\left(t_{2}\right)=E_{\mathrm{d}}, \quad$ i.e. $\quad U_{\mathrm{C} 4}(S)=U_{\mathrm{C} 6}(S)=E_{\mathrm{d}} / \mathrm{S}$. Then the resonant current $i_{\mathrm{r}}\left(t_{2}\right)=0$. For Fig. $5 \mathrm{~d}$, the following equation can be satisfied:

$$
\frac{1}{4 S C_{\mathrm{r}}} I_{\mathrm{r}}(S)+S L_{\mathrm{r}} I_{\mathrm{r}}(S)=\frac{E_{\mathrm{d}}}{2 S}
$$

The solution gives:

$$
I_{\mathrm{r}}(S)=E_{\mathrm{d}} \sqrt{\frac{C_{\mathrm{r}}}{L_{\mathrm{r}}}} \frac{\omega_{\mathrm{r}}}{S^{2}+\omega_{r}^{2}}
$$

Where: $\omega^{2}{ }_{r}=\frac{1}{4 L_{\mathrm{r}} C_{\mathrm{r}}}$

So that:

$$
i_{\mathrm{r}}\left(t-t_{2}\right)=E_{\mathrm{d}} \sqrt{\frac{C_{\mathrm{r}}}{L_{\mathrm{r}}}} \sin \omega_{\mathrm{r}}\left(t-t_{2}\right)
$$

at $t=t$, i.e. when $i_{\mathrm{r}}$ comes to its maximum, and makes a derivative with both parts of Equation (10). Moreover, let the left part be:

$$
\frac{\mathrm{d} i_{r}\left(t-t_{2}\right)}{\mathrm{d}\left(t-t_{2}\right)}=0, \text { then: } \cos \omega_{\mathrm{r}}\left(t_{1}-t_{2}\right)=0
$$

It can be obtained that:

$$
\Delta t^{\prime}=t-t_{2}=\frac{\pi}{2 \omega_{\mathrm{r}}}=\pi \sqrt{L_{\mathrm{r}} C_{\mathrm{r}}}
$$

In Fig. 5a, the voltage on capacitors $C_{4}$ and $C_{6}$ are:

$$
U_{\mathrm{C} 4}(S)=U_{\mathrm{C} 6}(S)=\frac{E_{\mathrm{d}}}{S}-S L_{\mathrm{r}} I_{\mathrm{r}}(S)-\frac{E_{\mathrm{d}}}{2 S}
$$

Substitute (8) into the above equation, then:

$$
U_{\mathrm{C} 4}(S)=U_{\mathrm{C} 6}(S)=\frac{E_{\mathrm{d}}}{2 S}-\frac{E_{\mathrm{d}}}{2} \cdot \frac{S}{S^{2}+\omega_{r}{ }^{2}}
$$

The solutions show that:

$$
u_{\mathrm{C} 4}\left(t-t_{2}\right)=u_{\mathrm{C} 6}\left(t-t_{2}\right)=\frac{E_{\mathrm{d}}}{2}\left[1-\cos \omega_{r}\left(t-t_{2}\right)\right]
$$

By substituting (11) into (14), it can be seen that the voltages on $C_{4}$ and $C_{6}$ comply with (15) when $i_{\mathrm{r}}$ comes to its maximum:

$$
u_{\mathrm{C} 4}\left(\Delta t^{\prime}\right)=u_{\mathrm{C} 6}\left(\Delta t^{\prime}\right)=\frac{E_{\mathrm{d}}}{2}
$$

When $C_{4}$ and $C_{6}$ discharge at $t=t_{3}$, their voltages become zero. Therefore, let (14) equals zero, which results in:

$$
\begin{aligned}
& \cos \omega_{r}\left(t_{3}-t_{2}\right)=1 \\
& \Delta t_{3}=t_{3}-t_{2}=\frac{\pi}{\omega_{\mathrm{r}}}=2 \pi \sqrt{L_{\mathrm{r}} C_{\mathrm{r}}}
\end{aligned}
$$

Integrating (16) and (10), i.e. at $t=t_{3}$, the resonant current $i_{\mathrm{r}}$ follows:

$$
i_{\mathrm{r}}\left(\Delta t_{3}\right)=i_{\mathrm{r}}\left(t_{3}-t_{2}\right)=0
$$

It can be seen that, when $i_{\mathrm{Lr}}$ reaches its maximum, the voltages on $C_{4}$ and $C_{6}$ decrease from $E_{\mathrm{d}}$ to $E_{\mathrm{d}} / 2$. This is due to the fact that when $u_{\mathrm{C} 4}\left(u_{\mathrm{C} 6}\right)>E_{\mathrm{d}} / 2$, the voltage on $L_{\mathrm{r}}$ is positive $\left(u_{\mathrm{C} 4}-E_{\mathrm{d}} / 2>0\right)$. Therefore, as $i_{\mathrm{Lr}}$ increases (for $\left.i_{\mathrm{Lr}}=i_{\mathrm{Lr}}\left(t_{2}\right)+i_{\mathrm{r}}\left(t-t_{2}\right)=i_{\mathrm{S}}+i_{\mathrm{r}}\left(t-t_{2}\right)\right)$, power accumulates gradually on $L_{r}$. Moreover, when $u_{\mathrm{C} 4}\left(u_{\mathrm{C} 6}\right)=E_{\mathrm{d}} / 2$, the voltage added on $L_{\mathrm{r}}$ becomes zero. Then $i_{\mathrm{Lr}}$ stops increasing, i.e. $i_{\mathrm{Lr}}$ comes to its maximum. As $C_{4}$ and $C_{6}$ discharge, $u_{\mathrm{C} 4}\left(u_{\mathrm{C} 6}\right)$ start to decrease until $u_{\mathrm{C} 4}\left(u_{\mathrm{C} 6}\right)<E_{\mathrm{d}} / 2$. Therefore, the voltage on $L_{\mathrm{r}}$ turns to be negative. Then due to the converse $L_{\mathrm{r}} \mathrm{d} i_{\mathrm{Lr}} / \mathrm{dt}, i_{\mathrm{Lr}}$ starts to decrease and release energy from $L_{\mathrm{r}}$, which equals the accumulated energy as mentioned above. Finally, at $t=t_{3}$, $i_{\mathrm{Lr}}=i_{\mathrm{Lr}}\left(t_{2}\right)+i_{\mathrm{r}}\left(t-t_{2}\right)=i_{\mathrm{S}}$.

3) Working time of the auxiliary switch $V_{A}$ : For the sake of convenience, Fig. 3 use a saw-tooth carrier with a positive slope for a comparison of the voltages. The time when $V_{A}$ is switched on or when resonance starts is determined by $u_{\mathrm{A}}$. As shown in Fig. 3, the time that $\mathrm{V}_{\mathrm{A}}$ closes is ahead of the vertical edges of the saw-tooth carrier, namely at $t_{1}$. According to the above analyzes in 1) and 2), the advance time shall be $\left(\Delta t_{2}+\Delta t_{3}\right)$.

Assume that the carrier period is $T_{\mathrm{c}}$, the reference voltage $u_{\mathrm{A}}$ can then be derived from:

$$
\frac{u_{\mathrm{A}}+1}{2}=\frac{T_{\mathrm{c}}-\left(\Delta t_{2}+\Delta t_{3}\right)}{T_{\mathrm{c}}}
$$

Or:

$$
u_{\mathrm{A}}=1-\frac{2\left(\Delta t_{2}+\Delta t_{3}\right)}{T_{c}}
$$

Substituting (7) and (16) into this yields:

$$
u_{\mathrm{A}}=X I+Y
$$

Where: $X=\frac{4 L_{\mathrm{r}}}{T_{\mathrm{c}} E_{\mathrm{d}}}$ and $Y=1-\frac{4 \pi \sqrt{L_{\mathrm{r}} C_{\mathrm{r}}}}{T_{\mathrm{c}}}, I=\left|i_{\mathrm{S}}\right|$

From Equation (19), the time that $\mathrm{V}_{\mathrm{A}}$ switches on should vary with changes in $i_{\mathrm{S}}$. In other words, it can follow the fluctuation of the load. However, the time when $\mathrm{V}_{\mathrm{A}}$ switches off should be behind of the vertical edges of the saw-tooth carrier, and its delay time should be longer than $\left(t_{4}-t_{3} \approx \Delta t_{3}\right)$.

A positive slope saw-tooth carrier can also be used to get solutions for the reference voltages $u_{\mathrm{A}}$ or $u_{\mathrm{B}}$ in all of the sections shown in Fig. 2. Equation (19) is also adaptable to all of the sections except that the reference current $I$ should be valued as bellow: 
Section 1 and $4, I=\left|i_{\mathrm{S}}\right|$

Section 2 and $5, I=\left|i_{\mathrm{R}}\right|$

Section 3 and $6, I=\left|i_{\mathrm{T}}\right|$

As above mentioned, when $\mathrm{V}_{\mathrm{A}}$ works, the resonance makes the input voltage of the bridges periodically decrease to zero, which provides the ZVS condition for the switches in the lower bridges. On the other hand, when $\mathrm{V}_{\mathrm{B}}$ works, the resonance will periodically increase the input voltage of the bridges to $E_{\mathrm{d}}$, which creates ZVS for the switches in the upper bridges.

4) Design of the Resonance Parameters: The selection of resonance parameters considers not only achievement of zero-voltage soft-switching, but also the resonance time, the current and voltage stress, and additional losses, etc.

From (10) and (11), the maximum value for $i_{\mathrm{r}}$ can be deduced as follows:

$$
I_{\text {rmax }}=E_{\mathrm{d}} \sqrt{\frac{C_{\mathrm{r}}}{L_{\mathrm{r}}}}=\frac{E_{\mathrm{d}}}{Z_{\mathrm{r}}}
$$

Where, the resonance impedance $Z_{\mathrm{r}}=\sqrt{\frac{L_{\mathrm{r}}}{C_{\mathrm{r}}}}$.

The resonant current $i_{\mathrm{r}}$ affects the current stress, the on-state losses, and the turn-off losses of the auxiliary switches. Since the DC voltage $E_{\mathrm{d}}$ is related to the modulation ratio $M$, according to (20), the adjustable parameter affecting the resonant current is $Z_{\mathrm{r}}$

From the viewpoint of reducing loss, it is hoped that the resonant current is as small as possible, i.e. $Z_{\mathrm{r}}$ is as large as possible. This can be achieved by increasing $C_{\mathrm{r}}$ or by reducing $L_{\mathrm{r}}$. However, too much $Z_{\mathrm{r}}$ can also cause problems.

The resonant capacitor $C_{\mathrm{r}}$ should be optimized to ease the main switch turn-off loss in case it is too small [18].

Since $L_{\mathrm{r}}$ is related to the load current, too large a value for $L_{\mathrm{r}}$ might cause a prolonged rise time for $i_{\mathrm{r}}$, and it might affect the normal resonance.

Therefore, the determination of $Z_{\mathrm{r}}$ should meet with the resonance time at first, and consider the circuit loss [19].

The maximum commutation time $\left(\Delta t_{2}+\Delta t_{3}\right)$ should be smaller than the switching dead time $t_{\text {dead }}$ of traditional hard-switching inverters, i.e. $\Delta t_{2}+\Delta t_{3}<t_{\text {dead }}$. According to Equations (7) and (16), $\left(\Delta t_{2}+\Delta t_{3}\right)$ can be expressed as:

$$
\frac{2 L_{\mathrm{r}} I_{\text {Smax }}}{E_{\mathrm{d}}}+2 \pi \sqrt{L_{\mathrm{r}} C_{\mathrm{r}}} \leq \Delta t_{2}+\Delta t_{3}<t_{\text {dead }}
$$

Where, $I_{\mathrm{Smax}}$ is the maximum for $i_{\mathrm{s}}$.

The resonant frequency $\omega_{\mathrm{r}}$ should be set by optimizing the current stress, the on-state losses and the turn-off losses of the auxiliary switches.

With the load current $I_{\text {Smax }}$, the resonance current $I_{\text {rmax }}$, and the optimized resonant capacitor $C_{\mathrm{r}}$, the resonant inductance $L_{\mathrm{r}}$ is decided.

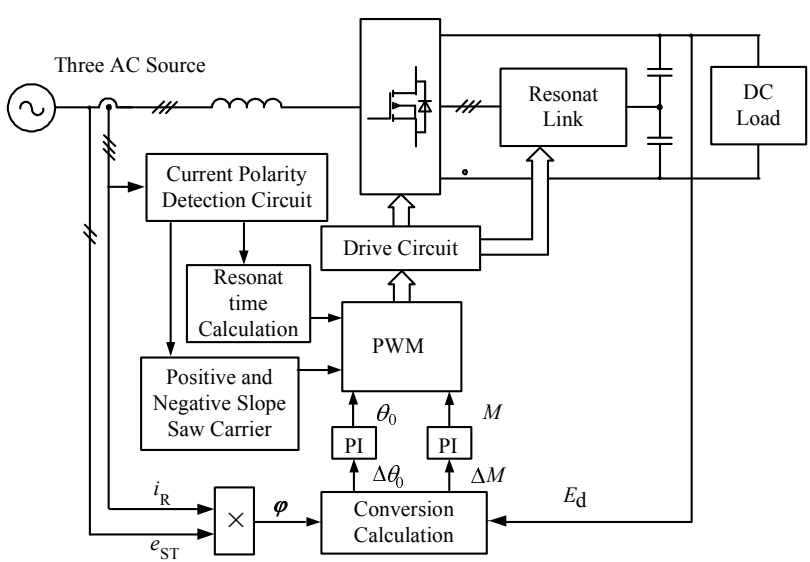

Fig. 6. Block diagram of control system.

\section{SIMULATION AND EXPERIMENTAL RESULT}

\section{A. Control System}

The control system shown in Fig. 6 includes two parts:

One part aims at realizing power factor correction (PFC) and keeping the DC-bus voltage constant. By measuring the line voltage $e_{\mathrm{ST}}$ and phase current $i_{\mathrm{R}}$, the power factor angle $\varphi$ can be obtained after phase discrimination. Then it is transformed as the angle offset $\Delta \alpha$, which is used in the PI regulator for phase control. By probing the DC bus voltage $E_{\mathrm{d}}$, the value is transformed into the modulation ratio offset $\Delta M$, which is used in the PI regulator for voltage control. The two PI regulators are realized by the following software algorithm:

$$
\begin{aligned}
\theta_{0}(n+1) & =\theta_{0}(n)+\left(k \Delta \theta_{0}+\int \Delta \theta_{0} d t\right) \\
M(n+1) & =M(n)+\left(k \Delta M+\int \Delta M d t\right)
\end{aligned}
$$

Based on the phase and amplitude control method, the three-phase modulation waves can be derived from Equation (2).

The other part is to ensure that the ARCP circuit works in the soft-switching state. By detecting the direction of the three-phase current, the saw-tooth carrier adopts a positive slope or a negative slope. Then it compares this with the modulation waves and the PWM drive signals can be produced. By measuring the amplitude of the phase current, the auxiliary switch drive signals can be obtained according to Equation (13).

\section{B. Current Feedback Control}

Fig. 7 shows the phasor adjusting method for the rectifying mode, where the lag angle $\theta_{0}$ is the angle between phasors $\dot{E}_{R}$ and $\dot{U}_{R} . U_{\mathrm{R}}$ is the virtual value of the fundamental component of phase R produced by PWM. It is deduced as: 


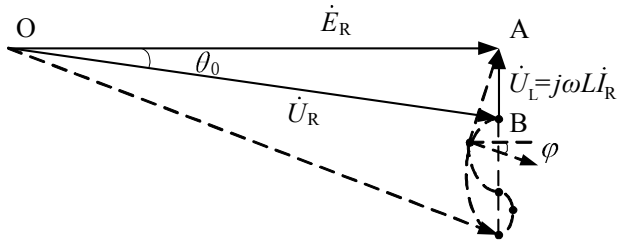

Fig. 7. The Phasor adjusting method for rectifying mode.

$$
U_{R}=\frac{M E_{d}}{\sqrt{3} \sqrt{2}}=\frac{M E_{d}}{\sqrt{6}}
$$

For improving the system dynamic response, the transition curve near the upright side of the triangle in Fig. 8 should be shortened. In Fig. 8 on the condition of ensuring a unity power factor and a constant DC-bus voltage, when there is a sudden load increase, the converter cannot offer a sudden current immediately to series inductance in input side of the converter, at the time only capacitors can offer the sudden current, thus the output DC current of the system next steady state is expressed by

$$
I^{*}{ }_{d}=I_{d}+I_{c}=I_{d}+C \frac{d u_{c}}{d t}
$$

By following the energy balance between the AC side and the DC side of the converter, the following is obtained:

$$
3 E_{R} I_{R}^{*}=E_{d} I_{d}^{*}=E_{d}\left(I_{d}+c \frac{d u_{c}}{d t}\right)
$$

For $u_{\mathrm{c}}$ is $E_{\mathrm{d}}$, with the right angle triangular diagram, (26) can be rewritten as:

$$
\tan \left(\theta_{0}+\Delta \theta_{0}^{\prime}\right)-\tan \theta_{0}=\frac{\omega L E_{d}}{3 E_{R}^{2}} C \frac{d E_{d}}{d t}
$$

Taking $\Delta \theta_{0}{ }^{\prime}$ as small, (27) is linearized as:

$$
\triangle \theta_{0}^{\prime} \approx k_{1} \frac{d E_{d}}{d t}
$$

where: $k_{1}=k_{0} \frac{\omega L C E_{d}}{3 E_{R}^{2}}, \quad k_{0} \approx \frac{\Delta \theta_{0}^{\prime}}{\tan \left(\theta_{0}+\Delta \theta_{0}^{\prime}\right)-\tan \theta_{0}}$

In a way similar to the $\Delta \theta_{0}{ }^{\prime}$ derivation, according to the right-angled triangle relations between phasors, the following is obtained:

$$
I_{R}^{*}=\frac{\left(M+\Delta M^{\prime}\right) E_{d}}{\sqrt{6} \omega L} \sin \left(\theta_{0}+\Delta \theta_{0}^{\prime}\right)
$$

The change of the modulation is deduced as:

$$
\Delta M^{\prime} \approx-\frac{k_{2} M \Delta \theta_{0}^{\prime}}{\sin \left(\theta_{0}+\Delta \theta_{0}^{\prime}\right)}+\frac{k_{3}}{\sin \left(\theta_{0}+\Delta \theta_{0}^{\prime}\right)} \frac{d E_{d}}{d t}
$$

where, $k_{2}$ and $k_{3}$ are the proportion factor.

When the second portion in (30) is small and can be omitted, (30) approximates to:

$$
\Delta M^{\prime} \approx-\frac{k_{2} M \Delta \theta_{0}^{\prime}}{\sin \left(\theta_{0}+\Delta \theta_{0}^{\prime}\right)}
$$

From (28) and (31), it is known that the variable load current is detected indirectly by a change of the DC voltage. This feeds the control system for the next steady state as an additional control variable to generate $\Delta \theta_{0}^{\prime}$ and $\Delta M^{\prime}$. Therefore, the system control equation is:

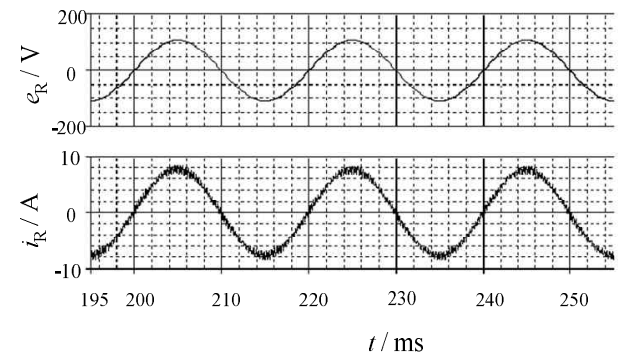

(a) Waves of voltage and current for Phase R.

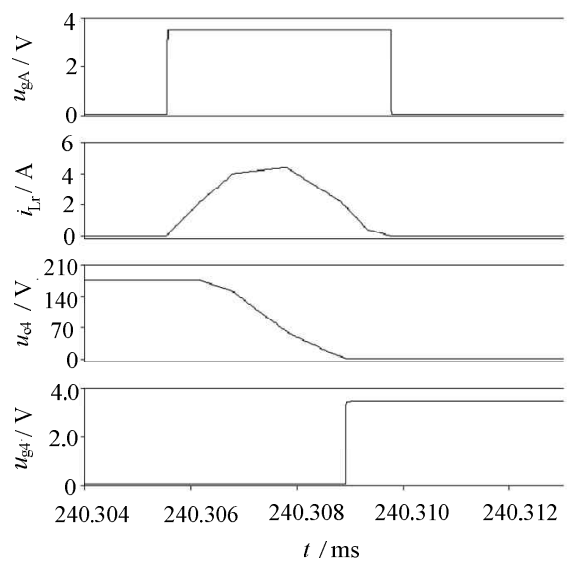

(b) Resonance waves.

Fig. 8. Simulation waveforms.

$$
\begin{aligned}
& \theta_{0}(n+1)=\theta_{0}(n)+\left(k \Delta \theta_{0}+\int \Delta \theta_{0} d t\right)+\Delta \theta_{0}^{\prime} \\
& M(n+1)=M(n)+\left(k \Delta M+\int \Delta M d t\right)+\Delta M^{\prime}
\end{aligned}
$$

\section{Simulation Verification}

Accordingly the control system in Fig. 6, a simulation model based on Pspice software is built. The main parameters used in the simulation are as follows:

Input line voltage: $110 \mathrm{~V}$

DC voltage: $190 \mathrm{~V}$

Inductors: $L_{\mathrm{R}, \mathrm{S}, \mathrm{T}}=7 \mathrm{mH}$

Split-capacitors: $C_{\mathrm{d} 1}=C_{\mathrm{d} 2}=1100 \mu \mathrm{F}$

Snubber capacitors: $C_{1 \sim 6}=8 \mathrm{nF}$

Resonant inductor: $L_{\mathrm{r}}=14 \mu \mathrm{H}$

Carrier frequency: $f_{\mathrm{c}}=3.3 \mathrm{kHz}$

Fig. 8 shows the simulation waveforms. In Fig. 8(a) the upper curve is the $\mathrm{R}$ phase voltage $e_{\mathrm{R}}$, and the lower curve is the $R$ phase current $i_{\mathrm{R}}$. In Fig. 8(b), from top to bottom, the curves are the voltage $u_{\mathrm{gA}}$ of the $\mathrm{V}_{\mathrm{A}}$ driver signal, the voltage $u_{\mathrm{c} 4}$ of snubber $C_{4}$, the current $i_{\mathrm{Lr}}$ of the inductor $L_{\mathrm{r}}$, and the voltage $u_{\mathrm{g} 4}$ of the $\mathrm{V}_{4}$ driver signal.

In Fig. 8, the input phase $R$ current keeps in phase with the source phase $R$ voltage. In the process of the system power conversion, the main switch turns on under the ZVS condition, and the auxiliary switch conducts in the ZCS state. The simulation results conform to the theory discussed previously. 


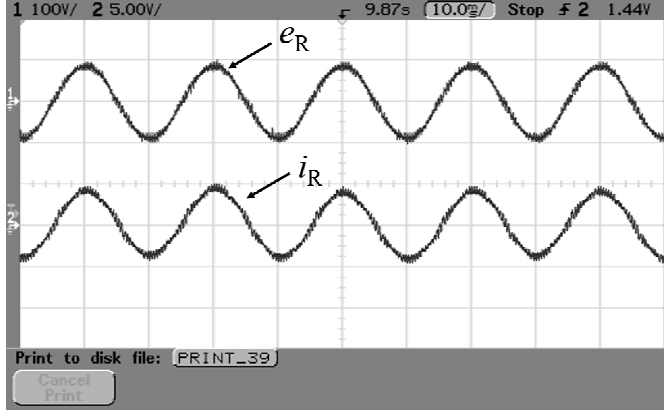

(a) Waves of voltage and current for Phase R.

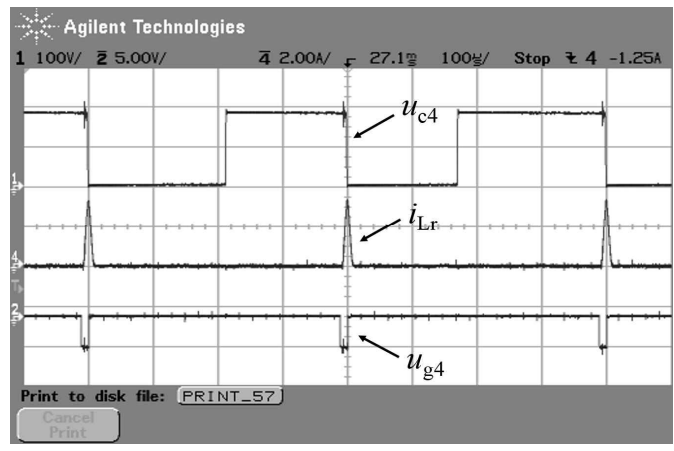

(b) Resonance on ZVS.

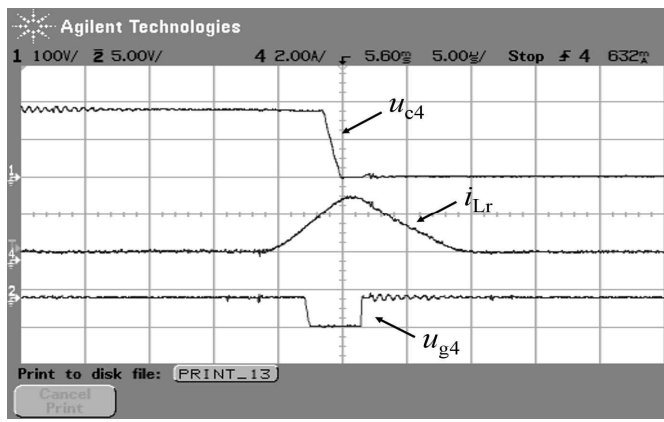

(c) Resonance on ZVS

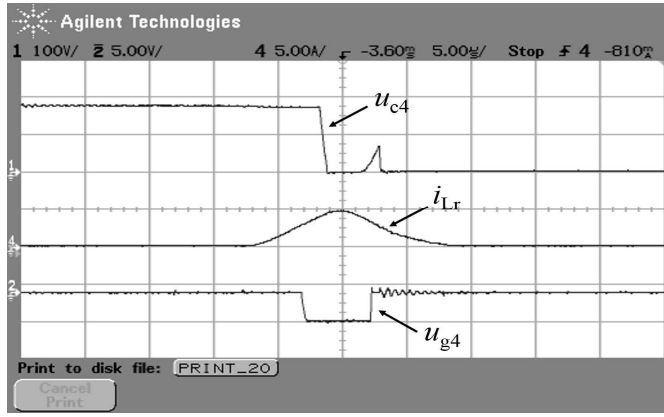

(d) Resonance not on ZVS

Fig. 9 Experimental waveforms.

\section{Experimental Results}

A $1 \mathrm{~kW}$ prototype system is constructed for experimental verification. The system control is implemented on a platform consisting of a digital signal processor (DSP). The main parameters used in the experiment are as same as those used in the simulation.

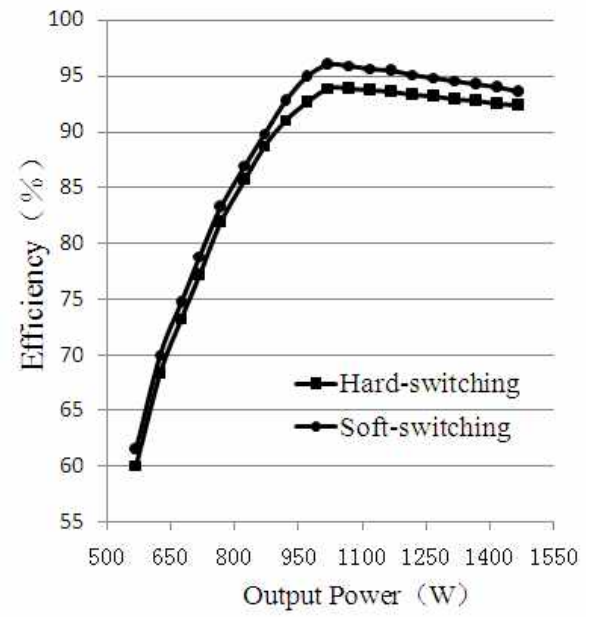

Fig. 10. Efficiency Comparison.

The experimental results obtained from the prototype system are shown in Fig. 9.

Fig. 9(a) shows in rectifying state, where the total input power factor $(\mathrm{PF})$ of the phase current is $99.85 \%$ and the total harmonic distortion (THD) is $5.4 \%$.

Fig. 9(b)-9(d) show the experimental waveforms for the resonance of the ZVS. Fig. 9(c) is a partially enlarged detail drawing of Fig. 9(b). As can be seen, when $u_{\mathrm{c} 4}$ is discharged to zero for resonance, the turning-on of $\mathrm{V}_{4}$ is in the zero voltage state.

Because the voltage of the snubber capacitor cannot change immediately, the power switches always turn off in zero voltage.

If the turning-on time of $G_{\mathrm{v} 4}$ is delayed $1 \mu \mathrm{s}$, the voltage $u_{\mathrm{c} 4}$ will rise owing to the energy of the resonant inductor, and the turning-on of $\mathrm{V}_{4}$ is not in the zero voltage state.

Fig. 10 shows the converter efficiency versus the output power. The efficiency of the soft-switching rectifier improves by about $2.1 \%$ at $1.02 \mathrm{~kW}$ when compared with the conventional SPWM hard-switching topology.

\section{CONCLUSIONS}

An auxiliary resonant commutated pole topology for three-phase PWM rectifiers is proposed. A detailed analysis and experiments are given based on its working principle, control strategy and resonant modes. Simulation and experiment results prove the consistency on a mathematical basis.

The proposed rectifier shows improvements on simpler structures when compared to the conventional ARCP while maintaining its efficiency. As a result, it is achieves cost-savings in hardware due to its simplified main circuit topology. Nonetheless, the minimum peak current in resonating and the least switching PWM mode enhance its advantages of high efficiency and easy control. 


\section{ACKNOWLEDGMENT}

The authors would like to acknowledge the financial support of the Program for Shanghai PuJiang Program (Grant No. 12PJ1403900) and Innovation Program of Shanghai Municipal Education Commission (Grant No. 13ZZ132).

\section{REFERENCES}

[1] S. Sato, Y. Suehiro, S. I. Nagai, and K. Morit, "High efficiency soft-switching 3-phase PWM rectifier," in Proc. INTELEC, pp. 453-460, Sep. 2000.

[2] J. Yoshitsugu, K. Inoue, E. Hiraki, and M. Nakaoka, "Resonant DC link snubber-assisted soft switching inverter type AC servo driver with low common mode current characteristics," in Proc. IEEE Conf. Power Electron. Drive Syst., pp.494-499, Oct. 2001.

[3] T. Ahmed, S. Nagai, M. Nakaoka, and T. Tanaka, "Utility-interactive four-switch three-phase soft-switching inverter with single resonant DC-link snubber and boost chopper," Journal of Power Electronics, Vol. 7, No. 2, pp.109-117, Apr. 2007.

[4] K. Q. Qu, C. B. Sun, G. C. Chen, C.Y. Xu, and T. Katsunori, "A PAC based three-phase zero-voltage soft-switching PWM converter," in Proc. IEEE the 4th IPEMC, Vol. 3, pp. 1091-1096, Aug. 2004..

[5] L. Rui, and D. H. Xu, "A Zero-Voltage Switching Three-Phase Inverter," IEEE Trans. Ind. Electron., Vol. 29, No. 3, pp.1200-1210, Mar. 2014.

[6] R. W. De Doncker and J. P. Lyons, "The auxiliary resonant commutated pole converter," in IEEE IAS Conf. Rec., pp. 1228-1235, Oct. 1990.

[7] E. Chu, M. Wu, L. Huang, X. Hou, and H. Zhang, "Research on a novel modulation strategy for auxiliary resonant commutated pole inverter with the smallest loss in auxiliary commutation circuits," IEEE Trans. Power Electron., Vol. 28, No. 3, pp. 1103-1117, Mar. 2013.

[8] Z. Y. Ma, D. H. Xu, R. Li, C. R. Du, and X. Zhang, "A novel dc-side zero-voltage switching (ZVS) three-phase boost PWM rectifier controlled by an improved SVM method," IEEE Trans. Power Electron., Vol. 27, No. 11, pp. 4391-4408, Nov. 2012.

[9] Q. Zhang, H. Hu, D. Zhang, X. Fang, Z. Shen, and I. Bartarseh, "A controlled-Type ZVS technique Without Auxiliary Components for the low power DC/AC inverter," IEEE Trans. Power Electron., Vol. 28, No. 7, pp. 3287-3296, Jul. 2013.

[10] M. Marvi and F. Ali, "A fully ZVS critical conduction mode boost PFC." Power Electronics," IEEE Trans. Power Electron., Vol. 27, No. 4, pp. 1958-1965, Apr. 2012.

[11] J. Aguillon-Garcia and G.-W. Moon, "A high-efficiency three-phase ZVS PWM converter utilizing a positive double-star active rectifier stage for server power supply," IEEE Trans. Ind. Electron., Vol. 58, No. 8, pp. 3317-3329, Aug. 2011.

[12] R.Corentin, F. Jean-Paul, Le, M. Philippe, D. Philippe, and L. Alain, "A simplified resonant pole for three-level soft-switching PFC rectifier used in UPS," IEEE Trans. Ind. Electron., Vol. 57, No. 8, pp. 2739-2746, Aug. 2010.

[13] W. Dong, J. Y. Choi, F. C. Lee, D. Boroyevich, and J. Lai, "Comprehensive evaluation of auxiliary resonant commutated pole inverter for electric vehicle applications," in Proc. IEEE PESC, Vol. 2, pp. 625-630, Jun. 2001.

[14] Y. Jang and M. M. Jovanovic, "The TAIPEI rectifier-a new three-phase two-switch ZVS PFC DCM boost rectifier," IEEE Trans. Ind. Electron., Vol. 28, No. 2, pp. 686-694, Aug. 2013.

[15] M. R. Amini, and H. Farzanehfard, "Three-phase soft-switching inverter with minimum components," IEEE Trans. Ind. Electron., Vol. 58, No. 6, pp. 2258-2264, Aug. 2011.

[16] K. Nishimura, K. Hirachi, A. M. Eid, H. W. Lee, and N. Nakaoka, "A novel prototype discontinuous inductor current mode operated three-phase PFC power converter with four active switches," in Proc. IEEE PESC, pp. 824-830, Jun. 2006.

[17] Q. Zhang, D. H. Zhang, H. B. Hu, J. Shen, and I. Batarseh, "Controlled-type ZVS technique without auxiliary components for micro-inverters," Journal of Power Electronics, Vol. 13, No. 6, pp. 919-927, Nov. 2013

[18] R. L. Steigerwald, R. W. De Doncker, and M. Kheraluwala, "A comparison of high power dc-dc soft switched converter topologies," IEEE Trans. Ind. Applicat., Vol. 32, No. 5, pp. 1139-1145, Sep./Oct. 1996.

[19] E. H. Chu, M. Y. Wu, L. Huang, X. Hou, and H. G. Zhang, "Research on a novel modulation strategy for auxiliary resonant commutated pole inverter with the smallest loss in auxiliary commutation circuits," IEEE Trans. Power Electron., Vol. 29, No. 3, pp. 1103-1117, Mar. 2014.

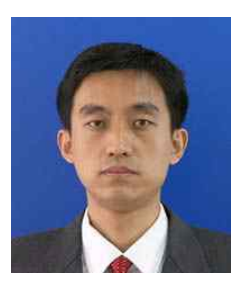

Ke-Qing Qu was born in China, in 1970. He received his $\mathrm{Ph} . \mathrm{D}$. degree in Electrical Engineering from Shanghai University, Shanghai, China, in 2004. He is currently an Associate Professor at the Shanghai University of Electric Power, Shanghai, China. He is also a Master Instructor. As a Visiting Scholar, he studied in Germany with full funding by the National Foundation for Study, from 2009 to 2010. He holds three Chinese patents and one monograph. He has published more than 40 technical papers in journals and conference proceedings. His current research interests include power electronic conversion, and new energy generation and its application to power systems.

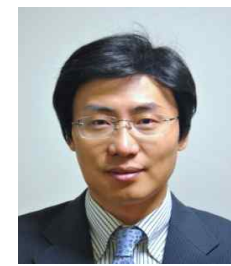

Jin-Bin Zhao (M'06) was born in China, in 1972. He received his M.S. and Ph.D. degrees in Electrical Engineering from Oita University, Oita, Japan, in 2002 and 2005, respectively. He worked as a Researcher at the R\&D Headquarters of the Origin Electric Co., Ltd, Japan, from 2005 to 2011. He is currently a Professor at the Shanghai University of Electric Power, Shanghai, China. He currently holds three U.S. patents and ten Japanese patents. He has published 60 technical papers in journals and conference proceedings. His current research interests include the control of power converters, soft-switching power converters, inverters, distributed power systems, power-factor correction and electric drive systems. Dr. Zhao is a Member of the Institute of Electrical and Electronics Engineers (IEEE), the Institute of Electrical Engineers of Japan (IEEJ), and the Institute of Electronics Information and Communication Engineers of Japan (IEICE). He is also a Senior Member of the China Power Supply Society. 